\title{
Delivery of a patient-friendly functioning report to improve patient-centeredness of dialysis care: a pilot study
}

Laura C. Plantinga ${ }^{1,2^{*}}$ (D) Brian Jones ${ }^{3}$, Jeremy Johnson ${ }^{3}$, Amelia Lambeth $^{3}$, Janice P. Lea ${ }^{1}$, Leigh Nadel ${ }^{1}$, Ann E. Vandenberg ${ }^{1}$ and C. Barrett Bowling ${ }^{4,5}$

\begin{abstract}
Background: Provider recognition of level of functioning may be suboptimal in the dialysis setting, and this lack of recognition may lead to less patient-centered care. We aimed to assess whether delivery of an app-based, individualized functioning report would improve patients' perceptions of patient-centeredness of care.

Methods: In this pre-post pilot study at three outpatient dialysis facilities in metropolitan Atlanta, an individualized functioning report-including information on physical performance, perceived physical functioning, and community mobility — was delivered to patients receiving hemodialysis $(n=43)$ and their providers. Qualitative and quantitative approaches were used to gather patient and provider feedback to develop and assess the report and app. Paired $t$ test was used to test for differences in patient perception of patient-centeredness of care (PPPC) scores (range, $1=$ most patient-centered to $4=$ least patient-centered) 1 month after report delivery.

Results: Delivery of the reports to both patients and providers was not associated with a subsequent change in patients' perceptions of patient-centeredness of their care (follow-up vs. baseline PPPC scores of 2.35 vs. 2.36; $P>$ 0.9). However, patients and providers generally saw the potential of the report to improve the patient-centeredness of care and reacted positively to the individualized reports delivered in the pilot. Patients also reported willingness to undergo future assessments. However, while two-thirds of surveyed providers reported always or sometimes discussing the reports they received, most (98\%) participating patients reported that no one on the dialysis care team had discussed the report with them within 1 month.

Conclusions: Potential lack of fidelity to the intervention precludes definitive conclusions about effects of the report on patient-centeredness of care. The disconnect between patients' and providers' perceptions of discussions of the report warrants future study. However, this study introduces a novel, individualized, multi-domain functional report that is easily implemented in the setting of hemodialysis. Our pilot study provides guidance for improving its use both clinically and in future pragmatic research studies, both within and beyond the dialysis population.
\end{abstract}

Keywords: Physical functioning, Patient-centered care, Patient-provider communication, Hemodialysis

\footnotetext{
* Correspondence: laura.plantinga@emory.edu

'Department of Medicine, Emory University, Atlanta, Georgia, USA

${ }^{2}$ Department of Epidemiology, Rollins School of Public Health, Emory

University, Atlanta, Georgia, USA

Full list of author information is available at the end of the article
}

(c) The Author(s). 2019 Open Access This article is distributed under the terms of the Creative Commons Attribution 4.0 International License (http://creativecommons.org/licenses/by/4.0/), which permits unrestricted use, distribution, and reproduction in any medium, provided you give appropriate credit to the original author(s) and the source, provide a link to the Creative Commons license, and indicate if changes were made. The Creative Commons Public Domain Dedication waiver (http://creativecommons.org/publicdomain/zero/1.0/) applies to the data made available in this article, unless otherwise stated. 


\section{Background}

Providing patient-centered care in the setting of dialysis is challenging and may require a significant shift in practice $[1,2]$. For example, patient-provider discussion of physical functioning is outside the scope of usual dialysis care. However, such discussions could lead to better recognition of function-related issues and to more patient-centered communication, which fosters the patient-provider relationship, responds to patient emotions, exchanges information, and enables shared decision-making and disease- and treatment-related patient behavior [3].

Decreased physical functioning is common in dialysis [4-12]; is a strong predictor of increased mortality, morbidity, and healthcare utilization [10, 13-17]; and is itself an important patient-centered outcome [18, 19] among patients receiving dialysis. However, recognition of poor physical functioning by dialysis providers is suboptimal [20]. Despite this, there are no interventions to improve recognition or facilitate discussion of physical functioning in this population. Thus, we aimed to design an app that can be used to collect data on physical functioning and generate an individualized report of patients' relative multi-domain functional status. We then conducted a pilot study to measure patient perceptions of patientcenteredness before and after delivery of the app-based report to patients receiving hemodialysis and their providers.

\section{Methods}

\section{Report and app development}

\section{Development of initial report}

The initial report was generated by the [INstant Functional Outcomes Report for Meaningful Encounters in Dialysis (INFORMED)] team. The report included: $(i)$ physical performance [Short Physical Performance Battery (SPPB), total score scale 0-12 (subscales of balance, gait speed, and chair stands scale $0-4)$; higher scores = better performance] [21]; (ii) patient-reported perceived physical functioning [Physical Functioning (PF) score (scale 0-100; higher scores = higher perceived functioning) included in the Kidney Disease Quality of Life] [22]; (iii) patient-reported activity limitations [basic activities of daily living (BADLs) [23] and instrumental activities of daily living (IADLs)] [24]; (iv) patient-reported history of falls from items assessing falls and their causes in the previous year and fear of falling during daily tasks [Falls Efficacy Scale (scale 0-100; higher scores = greater fear of falling; score $\geq 70=$ fear of falling)] [25]; and $(v)$ patient-reported community mobility [UAB Study of Aging Life-Space Assessment (LSA) instrument, with modifications excluding travel to the dialysis center; scale $0-120$, higher scores $=$ greater community mobility] [26]. This initial report (Additional file 1: Figure S1, left), representing a hypothetical patient on hemodialysis, was reviewed by our Advisory Group and a literacy expert before it was used in focus groups.

\section{Focus groups}

Methods for the INFORMED focus groups have been described [27]. Briefly, focus group participants were purposively recruited at three Emory-affiliated dialysis centers for four 90-min focus groups (held in 3/17; two with patients receiving hemodialysis, one with physicians, and one with nurses, social workers, and dietitians). Participants were provided a copy of the hypothetical report, and discussions about the report were recorded and transcribed verbatim. Feedback from all four groups was used to make final changes to the report prior to app development.

\section{App development}

The development team used an agile software development project management process, in which the research team described the desired features of the app. User feedback on the app was sought and captured in an iterative development process, in which current features were improved and new features added, until the delivery of the final working app. The app's primary functions were to support researchers in administration of the various patient assessments, generate and print the resulting physical functioning reports to a wireless printer, and capture that data for later use by researchers. The app guided the researcher through administration of each assessment, including recording of responses by the researcher and integrated timers and verbal script prompts for the SPPB. When assessments were completed, the app generated a physical functioning report that could be printed and exported.

\section{Pilot study \\ Recruitment}

All patients receiving in-center hemodialysis on the second and third shifts of two dialysis facilities were targeted for recruitment via phone call $(2 / 18-7 / 18 ; n=246)$. Of the $N=105$ patients reached via phone or self-referral, $N=52$ agreed to participate. Of these, $N=43$ completed the baseline study visit (Additional file 1: Figure S2).

\section{Patient study visits}

In the baseline visit, measurement of physical performance via the SPPB was performed before a scheduled dialysis session to minimize the risk of falls due to postdialysis hypotension; Mondays and Tuesdays were excluded due to potential effects of a 3-day interdialytic period. Self-reported information on functioning was collected via survey while the patient dialyzed on the same day. The entire assessment via app took approximately $30 \mathrm{~min}$. All functioning data were entered into 
the INFORMED app. Patients were also surveyed during the baseline visit about the patient-centeredness of dialysis care using a modified version of the Patient Perception of Patient-centeredness of Care (PPPC) [28] survey (Additional file 1: Table S1). In the 1-month follow-up visit, patients were surveyed while dialyzing using the same PPPC instrument and a survey about the utility of the report (Additional file 1: Table S2), and data were entered into REDCap [29].

\section{Report delivery}

Individualized paper reports were delivered to patient participants immediately after measurements were completed. Reports were delivered via secure email to the patient's providers (nephrologist, social worker, dietitian) within 2 days of the baseline study visit. Reports were also uploaded to the dialysis facilities' electronic health record (EHR); access instructions were included in the initial emails sent to providers with the reports (Additional file 1: Box S1). Monthly reminders to review the reports were sent to all providers who had received reports that month, in the week prior to interdisciplinary rounds (Additional file 1: Box S1).

\section{Provider survey}

When all baseline patient visits were complete, all providers who had received $\geq 1$ report $(n=17)$ were asked to complete a survey regarding the utility of the survey (Additional file 1: Table S3). The online survey was distributed via email, and responses and data were collected and managed via REDCap [29].

\section{Statistical analysis}

Patient characteristics, including PPPC scores, functioning data, and demographic and clinical data (obtained from the patients' dialysis records via linkage), were summarized. Baseline and follow-up PPPC scores were calculated as the mean of all 14 items; subscores were calculated similarly [28] (Additional file 1: Table S1). Paired $t$ tests were used to compare follow-up vs. baseline PPPC scores. Responses to quantitative items on the patient and provider utility surveys (Additional file 1: Tables S2 and S3) were reported as percentages. All analyses were performed with Stata v 14.2 (College Station, TX). Supplementary figures to visualize intersecting sets of impairments were created using apps in R [30,31].

\section{Results}

\section{Functioning report development}

Patients (mean age, 53) in the focus groups were primarily $(88 \%)$ black and predominantly male $(65 \%)$; in contrast, about half of providers in the focus groups (mean age, 49) were black (53\%) and $65 \%$ of providers were female (Table 1). Generally, all stakeholder groups discussed the potential of the report to improve the patient-centeredness of care and, particularly, to track function longitudinally; patients and providers alike felt the utility of the report could be limited by the time and space restrictions of the dialysis facility and for patients whose function was either very low or high (Table 1).

Based on feedback from all stakeholder groups, we made several changes to the initial report (Additional file 1: Figure S1). Figure 1 shows the final report delivered to patient participants and providers in the pilot study. We also made changes to the pilot study protocol based on focus group feedback, including: $(i)$ in-person training presentations at physician meetings and recorded webinars available on our study website [32]; (ii) delivery of reports to non-physician as well as physician providers; and (iii) delivery of electronic versions of the report to providers, both by email and uploaded to the EHR.

\section{Pilot study \\ Participants}

Of the 105 participants we contacted, 52 were scheduled for a baseline visit, and 43 completed the first visit and received individualized reports [recruitment rate $=41.0 \%$; retention rate $=82.7 \%$; Additional file 1: Figure S2]. All participants who completed the first study visit completed the second visit [mean (SD) days between visits = 31.1 (6.1)]. On average, patients in the pilot were 57 years old; $49 \%$ were female and $92 \%$ were black (Table 2 ). Median scores for SPPB, perceived functioning, and LSA were 8,65 , and 54 ; however, we observed scores across the entire possible ranges. More than half of participants (56\%) reported impairment in at least one IADL; $44 \%$ reported impairment in at least one BADL. More than onethird (35\%) reported falling in the prior year (Table 2). Younger vs. older participants generally had higher functioning across all domains, although variability was high (Additional file 1: Table S4). While male participants had higher functioning across most domains than female participants, the differences were generally not statistically significant (Additional file 1: Table S4). Pairwise correlations between domains were weak to moderate, although perceived physical functioning was strongly associated with physical performance, BADLs/IADLs, and life-space scores (Additional file 1: Table S5). Visualization of functioning impairments suggested multiple patterns involving different domains of function among individuals in the cohort (Additional file 1: Figure S3).

\section{Reported patient-centeredness}

At baseline, the mean total PPPC score was 2.36 (possible range 1-4, with lower scores indicating perceptions of more patient-centered care), while mean subscores indicating patients' perceptions that illness experiences were explored, that common ground was found, and that 
Table 1 Characteristics of and general functioning report feedback from participants in the focus group, 3/17

\begin{tabular}{|c|c|c|}
\hline & Patients Receiving Hemodialysis & Hemodialysis Providers \\
\hline No. of patients & 17 & 17 \\
\hline No. of focus groups ${ }^{*}$ & 2 & 2 \\
\hline \multicolumn{3}{|l|}{ Participant Characteristics } \\
\hline Mean age, years & 53 & 49 \\
\hline$\%$ male & $65 \%$ & $24 \%$ \\
\hline$\%$ black & $88 \%$ & $53 \%$ \\
\hline $\begin{array}{l}\text { Mean years on } \\
\text { dialysis/treating } \\
\text { kidney patients }\end{array}$ & 8 years & 12 years \\
\hline \multicolumn{3}{|l|}{ Report Feedback } \\
\hline \multicolumn{3}{|c|}{ Perceived uses of the report: } \\
\hline $\begin{array}{l}\text { Facilitation of } \\
\text { individualized/ } \\
\text { patient-centered } \\
\text { care }\end{array}$ & $\begin{array}{l}\text { "[l]t's a gauge for each individual that has issues in their own } \\
\text { way to address with a doctor." } \\
\text {-Patient group } 1 \\
\text { "I think, if this is done more with dialysis patients a lot of things } \\
\text { that transcends like weight gain, weight losses, and all that stuff } \\
\text { can be controlled better. And you get a better understanding } \\
\text { with the doctor and the patient on what they could do in order } \\
\text { to kind of bring that into focus, you know, more readily with } \\
\text { the patient." } \\
\text {-Patient group } 1\end{array}$ & $\begin{array}{l}\text { "If I got a report like this ... for example, this patient can } \\
\text { easily feed themselves, but going grocery shopping and } \\
\text { preparing their own food is not likely to happen. So this } \\
\text { patient could benefit from a Meals-on-Wheels type } \\
\text { program." } \\
\text {-Non-physician group } \\
\text { "It's good to build a rapport with your patients. You } \\
\text { know, just talking to them about their status, functioning } \\
\text { status, and offering support. So I think that's a good way } \\
\text { to ... kind of build trust with them as well." } \\
\text { —-Non-physician group }\end{array}$ \\
\hline $\begin{array}{l}\text { Potential } \\
\text { longitudinal use }\end{array}$ & $\begin{array}{l}\text { "I would take this whole chart and try to make it better." } \\
\text { —Patient group } 2\end{array}$ & $\begin{array}{l}\text { "I can see where you could use the tool serially and } \\
\text { someone is either getting better or worse." } \\
\text { —-Physician group }\end{array}$ \\
\hline \multicolumn{3}{|c|}{ Perceived limitations of the report: } \\
\hline $\begin{array}{l}\text { Limitations in the } \\
\text { dialysis facility } \\
\text { setting }\end{array}$ & $\begin{array}{l}\text { "I don't think the dialysis clinic would be the setting for } \\
\text { something like this, I think it would be somewhere where you } \\
\text { schedule an appointment at the convenience of the patient's } \\
\text { schedule or when the patient feels like they're up to [it]." } \\
\text {-Patient group } 1\end{array}$ & $\begin{array}{l}\text { "Some of them have transportation [issues], they have to } \\
\text { leave right away, they don't have time to sit with you. } \\
\text { Some prefer ... more confidentiality, so it just depends, I } \\
\text { think." } \\
\text {-Non-physician group }\end{array}$ \\
\hline $\begin{array}{l}\text { Limitations when } \\
\text { functioning is very } \\
\text { high or low }\end{array}$ & $\begin{array}{l}\text { "Well it is OK for people that's physically able to do it, but } \\
\text { people like me [in a wheelchair] that's not physically able, I } \\
\text { would score } 0 \text { on every one of them." } \\
\text { - Patient group } 1\end{array}$ & $\begin{array}{l}\text { "Obviously if you have amputations, like a lot of people } \\
\text { do, or if you can't walk or get up, you can't do any of } \\
\text { this, you'd get a zero. But you may have some functional } \\
\text { capacity; if you're in a wheelchair you might be able to } \\
\text { wheel yourself around." } \\
\text { - Physician group }\end{array}$ \\
\hline
\end{tabular}

${ }^{{ }^{*}}$ For providers, focus groups were split by discipline: physicians and physician extenders vs. nurses, social workers, and dietitians

the provider viewed the patient as whole person were $2.17,2.51$, and 1.67 , respectively (Table 2 ). At 1-month follow-up, PPPC scores were not statistically significant different from baseline scores.

\section{Patient-reported experiences with the report}

At follow-up, 42/43 (97.7\%) of patients reported that no one on the dialysis care team had discussed the report with them (Table 3). Among these 42 patients, $40.5 \%$ reported wanting to discuss the report with their provider, $11.9 \%$ brought up the report themselves, and $35.7 \%$ discussed it with someone outside of the dialysis care team. While none discussed with primary care or other nondialysis providers or with spiritual advisors, many discussed it with family and friends (Table 3). More than half $(54.8 \%)$ planned to discuss the report in a future visit with a provider (Table 3). All patients reported willingness to undergo future functioning assessment, at frequencies ranging from monthly/every 3 months (69.8\%) to annually (Table 3 ).

\section{Provider-reported experiences with the report}

Of the 17 providers contacted, 12 (70.6\% response rate) completed the survey $(8 / 18-9 / 18)$. Provider type and responses are displayed in Table 4 . Nearly half (41.7\%) reported that no training was needed to increase comfort with discussing the report (Table 4). Most providers reported always (16.7\%) or sometimes $(50.0 \%)$ discussing the report with patients (Table 4). While most reported rarely or never providing recommendations based on the report, the most common recommendations listed by providers were patient-driven exercise programs and 


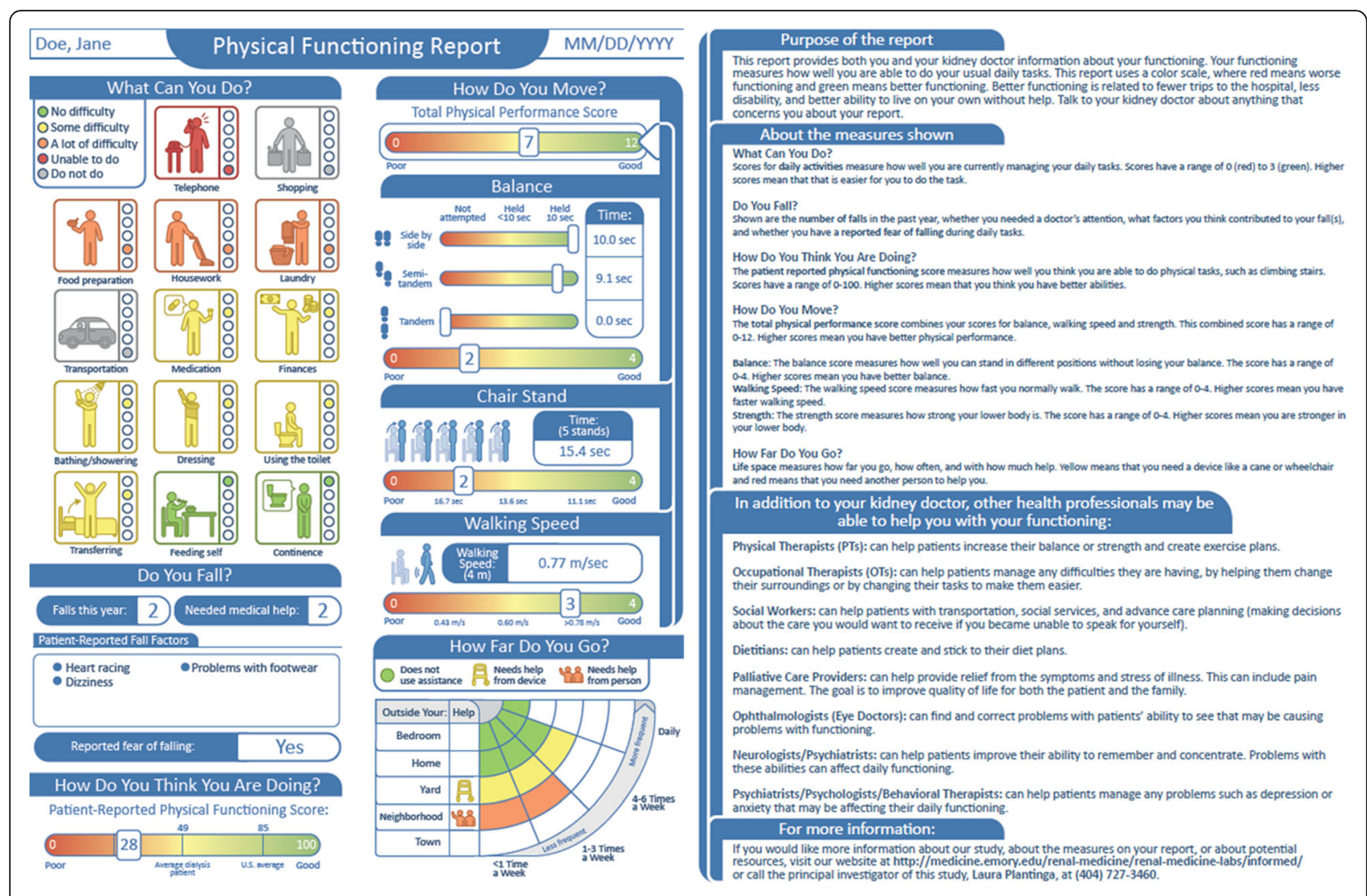

Fig. 1 Final physical functioning report incorporating focus group feedback and delivered to patients and providers in the pilot study

family consults. Most (87.5\%) felt comfortable discussing the report. More than a third (37.5\%) felt the report led to better communication with their patients (Table 4) because, for example, "results can be used to address ADLs" and "report disclosed information patient did not share with me or the care team." For providers who suggested the functioning report did not improve communication, most stated that communication was already good with the patient(s). No providers felt they were unqualified to discuss the report, that it was not their role to discuss the report, or that the information was not important for patient care (Table 4).

\section{Discussion}

In this pilot study of patients receiving hemodialysis and their providers, patient and provider reactions to the individualized functioning reports provided in the study were generally positive. However, while two-thirds of surveyed providers reported always or sometimes discussing the reports they received, most (98\%) participating patients reported that no one on the dialysis care team had discussed the report with them at the time of survey. Delivery of the reports to both patients and providers was not associated with a subsequent change in patients' perceptions of patient-centeredness of their care (follow-up vs. baseline PPPC scores of 2.35 vs. 2.36; $P>0.9$ ).

Potential lack of fidelity to the intervention (i.e., lack of provider discussion of the report during encounters within 1 month of receipt) might explain our null results with respect to patient-centeredness of care. It is also possible that delivery of this individualized report would have had no effect on this score in the limited timeframe of our study. Additionally, the PPPC score [28] may not capture elements of patient-centeredness that are important specifically in hemodialysis care. Finally, the scores, while in the middle of the range of possible scores $(1=$ most patient-centered to $4=$ least patientcentered), may already be maximized for in-center hemodialysis care as it is currently delivered in U.S. facilities, where provider visits are generally frequent but brief, and often unassociated with patient needs [33].

Interestingly, we observed a substantial mismatch between patients' and providers' responses regarding discussions of the report. If providers had discussions after the 1-month window, the lag between patient and provider surveys (up to 5 months for some patients) might partially explain this phenomenon. In fact, more than half (55\%) of patients indicated that they planned to discuss the report in a future visit. There may also be social 
Table 2 Characteristics and self-reported perceptions of patientcenteredness of care among 43 patients receiving hemodialysis who participated in the pilot, 2/18-8/18

\begin{tabular}{|c|c|}
\hline Characteristic & Overall \\
\hline \multicolumn{2}{|l|}{ Demographic and clinical characteristics } \\
\hline Age, mean (SD) & $56.5(13.7)$ \\
\hline Male, $n(\%)$ & $22(51.2 \%)$ \\
\hline Black race, $n(\%)$ & $36(92.3 \%)$ \\
\hline Median (IQR) years with ESRD & $3.0(1.4-6.2)$ \\
\hline \multicolumn{2}{|l|}{ Primary attributed cause of ESRD, $n(\%)$} \\
\hline Diabetes & $5(11.6 \%)$ \\
\hline Hypertension & $33(76.7 \%)$ \\
\hline Other & $5(11.6 \%)$ \\
\hline \multicolumn{2}{|l|}{ Functioning } \\
\hline Median (IQR) SPPB score & $8(4-9)$ \\
\hline Median (IQR) PF score & $65(40-80)$ \\
\hline Impaired in any BADL, $n(\%)$ & $19(44.2 \%)$ \\
\hline Impaired in any IADL, $n$ (\%) & $24(55.8 \%)$ \\
\hline Fell in past year, $n(\%)$ & $15(34.9 \%)$ \\
\hline Median (IQR) LSA score & $54(33-72)$ \\
\hline \multicolumn{2}{|l|}{ Perceptions of patient-centeredness of dialysis care } \\
\hline Mean (SD) PPPC total score, baseline & $2.36(0.74)$ \\
\hline Mean (SD) PPPC total score, follow-up & $2.35(0.62)$ \\
\hline$P^{*}$ for difference in score & $>0.9$ \\
\hline Mean (SD) subscore, experience explored, baseline & $2.17(0.78)$ \\
\hline Mean (SD) subscore, experience explored, follow-up & $2.01(0.74)$ \\
\hline$P^{*}$ for difference in score & 0.2 \\
\hline Mean (SD) subscore, common ground, baseline & $2.51(0.82)$ \\
\hline Mean (SD) subscore, common ground, follow-up & $2.58(0.66)$ \\
\hline$P^{*}$ for difference in score & 0.5 \\
\hline Mean (SD) subscore, whole person, baseline & $1.67(0.71)$ \\
\hline Mean (SD) subscore, whole person, follow-up & $1.60(0.69)$ \\
\hline$P^{*}$ for difference in score & 0.5 \\
\hline
\end{tabular}

$N=43$ for all variables listed, except race $(N=39)$ and years on dialysis $(N=41)$ $B A D L$ basic activity of daily living, ESRD end-stage renal disease, IADL instrumental activity of daily living, IQR interquartile range, $L S A$ Life-Space Assessment (scale, 0-120, higher scores greater community mobility), PF physical functioning subscale (scale 0-100, higher scores better perceived functioning), PPPC Patient Perception of Patient-Centeredness (scale, 1-4, lower scores more patient-centered), SPPB Short Physical Performance Battery (scale, $0-12$, higher scores better performance)

*By paired $t$ test. Note the statistical significance threshold, accounting for multiple testing overall and across subscales, would be 0.0125 , by conservative (Bonferroni) correction

desirability bias in the providers' responses regarding these discussions. However, patients and providers may also have different perceptions of "discussing the report"; e.g., if a physician reviewed a patient's report and made a referral or brought up issues based on the information in the report, without mentioning the report, the physician (but not the patient) may perceive this as a discussion of the report. Similarly, the limited health literacy that is common in this population [34] may be an issue: in fact, patients with earlier-stage kidney disease often report that they do not understand what the nephrologist told them during visits and often do not even recall that a kidney disease diagnosis was ever discussed [35].

This disconnect between patients' and providers' perceptions regarding the discussion of the functioning report is similar to that in a study by Wachterman et al. [36], in which seriously ill ( $\geq 20 \%$ physician-assessed risk of dying in the next year) hemodialysis patients and their nephrologists were interviewed regarding their perceived prognosis. In most cases, the patients were more optimistic than their nephrologists, with $81 \%$ of patients estimating they had $a \geq 90 \%$ chance of survival in the next year, whereas nephrologists estimated this prognosis for only $25 \%$ of these patients. In fact, none of the patients in the study reported having ever received a prognosis from their nephrologists [36], suggesting that provision of information might align patients' and providers' estimates and thus allow them to be "on the same page" in discussion of goals of care. However, much like the Study to Understand Prognoses and Preferences for Outcomes and Risks of Treatments (SUPPORT) trial [37], which showed timely delivery of information on prognosis and patient preferences had no effect on endof-life outcomes (including ratings of communication, knowledge of preferences for resuscitation, and highburden utilization such as intensive care and mechanical ventilation) among seriously ill hospitalized patients, the results of our study suggest that information alone may not be enough. In fact, information is likely a necessary, but not sufficient, component of the type of open-ended discussion of functioning-and the eliciting of goals of care and shared decision-making in the context of functioning-that would improve the patient-centeredness of care, at least in the challenging environment in which dialysis care is delivered. Further, while dialysis facilities have a built-in multidisciplinary team of nurses, social workers, and dietitians, who could potentially have such discussions and implement needed support services, the care plans are generally driven by the nephrologists. The nephrologists' action-oriented responses in our preliminary qualitative study, in which they expressed discomfort at receiving information that could not act upon and even expressed preferences for having a separate report to protect patients from receiving potentially negative information, suggest that willingness and/or ability to have such conversations is currently limited [27]. The lowest PPPC subscores we observed in this pilot were for "finding common ground," further suggesting this may be the primary communication barrier to patientcentered care in this population. Future studies in this population may be improved with engagement of 
Table 3 Patient experience with, and perceptions of the utility of, the functioning report, 3/18-8/18

\begin{tabular}{|c|c|}
\hline Item & $n(\%)$ \\
\hline No. (\%) responded & $43(100 \%)$ \\
\hline No. (\%) reported that anyone on the dialysis care team discussed report with them & $1(2.3 \%)$ \\
\hline \multicolumn{2}{|l|}{ Among 42 patients with complete follow-up: } \\
\hline No. (\%) wanted to discuss report with provider & $17(40.5 \%)$ \\
\hline No. (\%) brought up report with a dialysis provider themselves & $5(11.9 \%)$ \\
\hline No. (\%) discussed report with someone else not on dialysis care team & $15(35.7 \%)$ \\
\hline Primary care provider or other non-dialysis provider & $0(0.0 \%)$ \\
\hline Spouse & $5(11.9 \%)$ \\
\hline Child & $2(4.8 \%)$ \\
\hline Other relative & $8(19.1 \%)$ \\
\hline Friend & $2(4.8 \%)$ \\
\hline Spiritual or religious advisor & $0(0.0 \%)$ \\
\hline No. (\%) planned to discuss report in future visit with provider & $23(54.8 \%)$ \\
\hline \multicolumn{2}{|l|}{ Among all 43 patients: } \\
\hline \multicolumn{2}{|l|}{ No. (\%) willing to undergo routine testing to receive reports: } \\
\hline Monthly & $15(34.9 \%)$ \\
\hline Every 3 months & $15(34.9 \%)$ \\
\hline Every 6 months & $8(18.6 \%)$ \\
\hline Annually & $5(11.6 \%)$ \\
\hline Never & $0(0.0 \%)$ \\
\hline
\end{tabular}

geriatricians or geriatric interprofessional teams as an alternative to engagement of nephrologists, who have been trained in a disease-oriented approach to care, which is further reinforced by required quality reporting that does not prioritize patient-centeredness [1, 2, 38].

Most patients wanted to discuss the reports with their providers, and they were willing to undergo testing to have the reports available longitudinally. Providers indicated that functioning information was useful clinically, that they felt comfortable with the functioning information, and that they felt it was primarily the job of dialysis providers to discuss the information conveyed by the report. Among those who discussed the report, more than a third noted that it led to better communication with their patients. Not surprisingly, dialysis providers noted that limited time was a barrier to the use of the report. Some providers did not remember receiving reports, and only a few tried to view the reports on the dialysis EHR, suggesting that the mode and timing of delivery of the reports may have been suboptimal for dialysis providers.

Functioning scores among these patients were low, consistent with prior studies [4-12], but varied considerably between individuals, with entire ranges of scores represented. This variability, combined with the limited overlap between domains of functioning within individuals, suggest a high degree of individuality in functioning among patients receiving hemodialysis. The strength of the multi-domain functioning report we delivered is that it captures this individuality and allows providers at-aglance information on what interventions patients may need. For example, the providers in our pilot mentioned a wide variety of services (e.g., physical therapy, occupational therapy, depression work-up, and cognitive assessment) to which they referred based on the report. Importantly, the report also provides functioning information in a standardized way, avoiding the use of imperfect proxies of functioning (e.g., age or "eyeball test") that may be used by clinicians in the absence of other information.

There are additional limitations to this study worth nothing. Recruitment among patients receiving hemodialysis was difficult, and the possibility of selection bias due to differential recruitment remains. It is also possible that the reminders to complete surveys may have incentivized lagging providers to view or have discussions about the report before completing the survey. We did not include nurses because they did not have assigned patients; however, as the providers noted, nurses are an integral part of the interdisciplinary care team and likely necessary for successful clinical implementation of these reports. We also did not include patient caregivers. In fact, family and friends-many of whom were likely caretakers-were the most commonly included individuals on the list of people with whom the patient had discussed the report. While not within the 
Table 4 Hemodialysis provider experience with, and perceptions of the utility of, the functioning report, 8/18-9/18

\begin{tabular}{|c|c|}
\hline Item & $n(\%)$ \\
\hline No. (\%) completing survey & $12(70.6 \%)$ \\
\hline \multicolumn{2}{|l|}{ Type of hemodialysis provider } \\
\hline Nephrologist & $5(41.7 \%)$ \\
\hline Social Worker & $4(33.3 \%)$ \\
\hline Dietitian & $3(25.0 \%)$ \\
\hline No. (\%) reporting receiving 0 reports: & $2(16.7 \%)$ \\
\hline \multicolumn{2}{|l|}{ No. (\%) reporting that report should be discussed by: } \\
\hline Nephrologist & $8(66.7 \%)$ \\
\hline Nurse & $6(50.0 \%$ \\
\hline Social worker & $6(50.0 \%)$ \\
\hline Dietitian & $5(41.7 \%)$ \\
\hline Primary care provider & $3(25.0 \%)$ \\
\hline Other & $1(8.3 \%)$ \\
\hline No one & $0(0.0 \%)$ \\
\hline \multicolumn{2}{|l|}{ No. (\%) reporting discussing reports with patients: } \\
\hline Always & $2(16.7 \%)$ \\
\hline Sometimes & $6(50.0 \%)$ \\
\hline Never & $4(33.3 \%)$ \\
\hline \multicolumn{2}{|c|}{ No. (\%) reporting training would improve their comfort discussing report: } \\
\hline In-person training & $3(25.0 \%)$ \\
\hline Web training & $3(25.0 \%)$ \\
\hline Role modeling of provider-patient encounters & $2(16.7 \%)$ \\
\hline Other & $1(8.3 \%)$ \\
\hline No training needed & $5(41.7 \%)$ \\
\hline
\end{tabular}

Among 8 providers who always or sometimes discussed report with patients No. (\%) reporting who brought up report:

Patients brought it up more often

Provider brought it up more often

Patients/providers brought it up equally

No. (\%) reporting making recommendations after report discussion:

Frequently/sometimes

Rarely/never

$5(62.5 \%)$

No. (\%) reporting making recommendations for:

Physical therapy

$1(12.5 \%)$

Patient-driven exercise program

$2(25.0 \%)$

Occupational therapy/home assessment

$1(12.5 \%)$

Depression work-up

$1(12.5 \%)$

Cognitive assessment

$1(12.5 \%)$

New social service

$0(0.0 \%)$

Family consult

$2(25.0 \%)$

Other

None

No. (\%) reporting they felt comfortable discussing the report with patients

No. (\%) reporting that report led to better communication with patient 
Table 4 Hemodialysis provider experience with, and perceptions of the utility of, the functioning report, 8/18-9/18 (Continued)

\begin{tabular}{ll}
\hline Item & $n(\%)$ \\
\hline Among 10 providers who sometimes or never discussed report with patients & \\
No. (\%) reporting reasons for not discussing report: & $1(10.0 \%)$ \\
It was not appropriate to discuss & $0(0.0 \%)$ \\
Provider felt unqualified to discuss & $0(0.0 \%)$ \\
Provider felt it was not their role to discuss & $3(30.0 \%)$ \\
There was never enough time & $0(0.0 \%)$ \\
Information was not important for patient care & $1(10.0 \%)$ \\
Information was not actionable & $1(10.0 \%)$ \\
$\quad$ Provider forgot about report & $2(20.0 \%)$ \\
Provider did not receive report & $2(20.0 \%)$ \\
Other &
\end{tabular}

scope of this pilot study, having mandatory, scripted patient-provider discussions about the report may have mitigated concerns about the fidelity of the intervention, providing a better estimate of efficacy, rather than effectiveness. Additional measurements of patient-centeredness both before and after the delivery of the report might have captured changes more robustly, and the small sample size in this pilot precluded meaningful subgroup analyses. Finally, generalizability to populations of patients receiving hemodialysis that are older or have a different race/ethnicity or socioeconomic distribution from our metropolitan Atlanta population may be limited.

\section{Conclusions}

Despite its limitations, this pilot study introduces a novel, individualized, multi-domain functional report that is easily implemented via app in the setting of hemodialysis. Likely lack of fidelity to intervention precludes conclusions about the effect of delivery of the report on patient-centeredness of patient-provider communication. However, the disconnect between patients' and providers' perceptions of discussions of the report highlights that provision of information may not be sufficient to support the open-ended discussions of functioning needed for eliciting of goals and shared decision-making that are critical to patient-centered care; this warrants future study. Furthermore, our findings will inform future studies to improve implementation of the app and report in the dialysis population and beyond.

\section{Supplementary information}

Supplementary information accompanies this paper at https://doi.org/10. 1186/s12913-019-4733-6.

Additional file 1: Supplementary tables and figures.

\section{Abbreviations}

BADL: Basic Activity of Daily Living; IADL: Instrumental Activity of Daily Living; INFORMED: INstant Functional Outcomes Report for Meaningful Encounters in Dialysis; LSA: Life-Space Assessment; PF: Physical Functioning;
PPPC: Patient Perception of Patient-centeredness of Care; SPPB: Short Physical Performance Battery; SUPPORT: Study to Understand Prognoses and Preferences for Outcomes and Risks of Treatments

\section{Acknowledgements}

We thank the dialysis facility staff and patients who participated in and facilitated our study. We also thank the student research assistants who assisted with functioning assessment and surveys (Katherine Ross, Abyalew Sahlie, and Supriya Sarkar), coding (Kartik Prabu), and figure and table preparation (Lilian Paez Galarza and Grace Xu). Finally, we thank our advisory team members [Theodore (Ted) Johnson II, Rachel Patzer, Stephen Pastan, and Molly Perkins], C. David Byrd, and Katharina Echt, who provided valuable feedback on early versions of the report. This work was presented in part at the American Geriatrics Society 2019 Annual Scientific Meeting, held May 24, 2019, in Portland, Oregon.

\section{Authors' contributions}

$L C P, B J, A E V$, and CBB conceived and designed the study. $L N$, JPL, and AEV participated in subject recruitment and data acquisition. BJ, JJ, and AL provided technical support, including app development and graphic art. LCP and AEV analyzed the data. LCP drafted the manuscript and all authors read and approved the final manuscript.

\section{Funding}

This work was supported by the Extramural Grant Program (EGP) by Satellite Healthcare, a not-for-profit renal care provider. Emory University REDCap is supported by UL1 TR000424. Additional support for C.B.B. was provided by the National Heart, Lung, and Blood Institute (R01HL133618) and the Durham Center of Innovation to Accelerate Discovery and Practice Transformation (ADAPT), (CIN 13-410) at the Durham VA Health Care System. The funders had no role in the design of the study or collection, analysis, and interpretation of data or in writing the manuscript.

\section{Availability of data and materials}

De-identified versions of the datasets used in the current study are available from the corresponding author on reasonable request.

Ethics approval and consent to participate

This study was approved by the Emory University Institutional Review Board (protocol no. IRB00090023). Written informed consent was obtained from all focus group and pilot study participants.

Consent for publication

Not applicable.

\section{Competing interests}

Drs. Plantinga and Bowling serve on the editorial board of BMC Nephrology. The authors declare that they have no other competing interests. 


\section{Author details}

'Department of Medicine, Emory University, Atlanta, Georgia, USA. ${ }^{2}$ Department of Epidemiology, Rollins School of Public Health, Emory University, Atlanta, Georgia, USA. Interactive Media Technology Center, Georgia Institute of Technology, Atlanta, Georgia, USA. ${ }^{4}$ Durham Veterans Affairs Geriatric Research Education and Clinical Center, Durham Veterans Affairs Medical Center, Durham, North Carolina, USA. ${ }^{5}$ Department of Medicine, Duke University, Durham, North Carolina, USA.

Received: 7 January 2019 Accepted: 11 November 2019 Published online: 27 November 2019

\section{References}

1. O'Hare AM. Patient-centered care in renal medicine: five strategies to meet the challenge. Am J Kidney Dis. 2018;71:732-6.

2. Tong A, Winkelmayer WC, Wheeler DC, van Biesen W, Tugwell P, Manns B, et al. Nephrologists' perspectives on defining and applying patient-centered outcomes in hemodialysis. Clin J Am Soc Nephrol. 2017;12:454-66.

3. King A, Hoppe RB. "best practice" for patient-centered communication: a narrative review. J Grad Med Educ. 2013;5:385-93.

4. Hall YN, Larive B, Painter P, Kaysen GA, Lindsay RM, Nissenson AR, et al. Effects of six versus three times per week hemodialysis on physical performance, health, and functioning: frequent hemodialysis network (FHN) randomized trials. Clin J Am Soc Nephrol. 2012:7:782-94.

5. Kaysen GA, Larive B, Painter P, Craig A, Lindsay RM, Rocco MV, et al. Baseline physical performance, health, and functioning of participants in the frequent hemodialysis network (FHN) trial. Am J Kidney Dis. 2011;57:101-12.

6. Johansen KL, Chertow GM, da Silva M, Carey S, Painter P. Determinants of physical performance in ambulatory patients on hemodialysis. Kidney Int. 2001:60:1586-91.

7. Meyer KB, Espindle DM, DeGiacomo JM, Jenuleson CS, Kurtin PS, Davies AR. Monitoring dialysis patients' health status. Am J Kidney Dis. 1994;24:267-79.

8. Cook WL, Jassal SV. Functional dependencies among the elderly on hemodialysis. Kidney Int. 2008;73:1289-95.

9. Kutner NG, Zhang R, Allman RM, Bowling CB. Correlates of ADL difficulty in a large hemodialysis cohort. Hemodial Int. 2014;18:70-7.

10. Abdel-Rahman EM, Yan G, Turgut F, Balogun RA. Long-term morbidity and mortality related to falls in hemodialysis patients: role of age and gender - a pilot study. Nephron Clin Pract. 2011;118:c278-84.

11. Cook WL, Tomlinson G, Donaldson M, Markowitz SN, Naglie G, Sobolev B, et al. Falls and fall-related injuries in older dialysis patients. Clin J Am Soc Nephrol. 2006;1:1197-204.

12. Bowling CB, Muntner P, Sawyer P, Sanders PW, Kutner N, Kennedy R, et al. Community mobility among older adults with reduced kidney function: a study of life-space. Am J Kidney Dis. 2014;63:429-36.

13. Roshanravan B, Robinson-Cohen C, Patel KV, Ayers E, Littman AJ, de Boer IH, et al. Association between physical performance and all-cause mortality in CKD. J Am Soc Nephrol. 2013;24:822-30.

14. Painter P, Marcus R. Physical function and gait speed in patients with chronic kidney disease. Nephrol Nurs J. 2013;40:529-38.

15. Mapes DL, Lopes AA, Satayathum S, McCullough KP, Goodkin DA, Locatelli $F$, et al. Health-related quality of life as a predictor of mortality and hospitalization: the Dialysis outcomes and practice patterns study (DOPPS). Kidney Int. 2003;64:339-49.

16. DeOreo PB. Hemodialysis patient-assessed functional health status predicts continued survival, hospitalization, and dialysis-attendance compliance. Am J Kidney Dis. 1997;30(2):204-12.

17. Li M, Tomlinson G, Naglie G, Cook WL, Jassal SV. Geriatric comorbidities, such as falls, confer an independent mortality risk to elderly dialysis patients. Nephrol Dial Transplant. 2008;23:1396-400.

18. Bowling $C B, O^{\prime}$ Hare AM. Managing older adults with CKD: individualized versus disease-based approaches. Am J Kidney Dis. 2012;59:293-302.

19. O'Hare AM, Rodriguez RA, Bowling CB. Caring for patients with kidney disease: shifting the paradigm from evidence-based medicine to patientcentered care. Nephrol Dial Transplant. 2016;31:368-75.

20. Bowling $\mathrm{CB}$, Zhang $\mathrm{R}$, Franch $\mathrm{H}$, Huang $\mathrm{Y}$, Mirk A, McClellan WM, et al. Underreporting of nursing home utilization on the CMS-2728 in older incident dialysis patients and implications for assessing mortality risk. BMC Nephrol. 2015;16:32.
21. Guralnik JM, Simonsick EM, Ferrucci L, Glynn RJ, Berkman LF, Blazer DG, et al. A short physical performance battery assessing lower extremity function: association with self-reported disability and prediction of mortality and nursing home admission. J Gerontol. 1994:49:M85-94.

22. Hays RD, Kallich JD, Mapes DL, Coons SJ, Carter WB. Development of the kidney disease quality of life (KDQOL) instrument. Qual Life Res. 1994;3:329-38.

23. Katz S, Downs TD, Cash HR, Grotz RC. Progress in development of the index of ADL. Gerontologist. 1970;10:20-30.

24. Lawton MP, Brody EM. Assessment of older people: self-maintaining and instrumental activities of daily living. Gerontologist. 1969;9:179-86.

25. Tinetti ME, Richman D, Powell L. Falls efficacy as a measure of fear of falling. J Gerontol. 1990;45:P239-43.

26. Baker PS, Bodner EV, Allman RM. Measuring life-space mobility in community-dwelling older adults. J Am Geriatr Soc. 2003;51:1610-4.

27. Vandenberg AE, Bowling CB, Adisa O, Sahlie A, Nadel L, Lea J, Plantinga LC. Shared patient and provider values in end-stage renal disease decision making: identifying the tensions. Patient Educ Couns. 2019;102:1280-7.

28. Stewart M, Meredith L, Ryan, BL, Brown JB. The Patient Perception of Patientcentredness Questionnaire (PPPC). London: University of Western Ontario; 2004. Working Paper \#04-1. Available at: https:/www.schulich.uwo.ca/ familymedicine/research/csfm/publications/working_papers/the\%20patient\%2 Operception\%20of\%20patient\%20centerdness\%20questionnaire_pppc.html

29. Harris PA, Taylor R, Thielke R, Payne J, Gonzalez N, Conde JG. Research electronic data capture (REDCap)--a metadata-driven methodology and workflow process for providing translational research informatics support. J Biomed Inform. 2009:42:377-81.

30. Lex A, Gehlenborg N, Strobelt H, Vuillemot R, Pfister H. UpSet: visualization of intersecting sets. IEEE Trans Vis Comput Graph. 2014;20(12):1983-92.

31. Larsson J. eulerr: Area-Proportional Euler and Venn Diagrams with Ellipses (R package). Version 4.1.0. Available at: https://cran.r-project.org/package=eulerr .

32. Plantinga LC. INFORMED Study. Available at: http://medicine.emory.edu/ geriatrics-gerontology/labs/plantinga-lab/index.html.

33. Erickson KF, Tan KB, Winkelmayer WC, Chertow GM, Bhattacharya J. Variation in nephrologist visits to patients on hemodialysis across dialysis facilities and geographic locations. Clin J Am Soc Nephrol. 2013;8:987-94.

34. Taylor DM, Fraser SDS, Bradley JA, Bradley C, Draper H, Metcalfe W, et al. A systematic review of the prevalence and associations of limited health literacy in CKD. Clin J Am Soc Nephrol. 2017;12:1070-84.

35. Lederer S, Fischer MJ, Gordon HS, Wadhwa A, Popli S, Gordon EJ. Barriers to effective communication between veterans with chronic kidney disease and their healthcare providers. Clin Kidney J. 2015;8:766-71.

36. Wachterman MW, Marcantonio ER, Davis RB, Cohen RA, Waikar SS, Phillips RS, McCarthy EP. Relationship between the prognostic expectations of seriously ill patients undergoing hemodialysis and their nephrologists. JAMA Intern Med. 2013;173:1206-14.

37. The SUPPORT Principal Investigators. A controlled trial to improve care for seriously ill hospitalized patients: the study to understand prognoses and preferences for outcomes and risks of treatment (SUPPORT). JAMA. 1995;274:1591-8.

38. Gupta N, Wish JB. Do current quality measures truly reflect the quality of dialysis? Semin Dial. 2018;31:406-14.

\section{Publisher's Note}

Springer Nature remains neutral with regard to jurisdictional claims in published maps and institutional affiliations.

\section{Ready to submit your research? Choose BMC and benefit from:}

- fast, convenient online submission

- thorough peer review by experienced researchers in your field

- rapid publication on acceptance

- support for research data, including large and complex data types

- gold Open Access which fosters wider collaboration and increased citations

- maximum visibility for your research: over $100 \mathrm{M}$ website views per year

At $\mathrm{BMC}$, research is always in progress.

Learn more biomedcentral.com/submission 